\title{
La televisión educativa en España: la oferta de Atresmedia, Mediaset y RTVE
}

\section{(Educational Television in Spain: the offer of Atresmedia, Mediaset and RTVE)}

\author{
Marta Rodríguez-Castro \\ Universidade de Santiago de Compostela, USC (España) \\ Ana María López-Cepeda \\ Universidad de Castilla-La Mancha, UCLM (España) \\ Xosé Soengas-Pérez \\ Universidade de Santiago de Compostela, USC (España)
}

DOI: https://doi.org/10.5944/ried.25.1.30952

\section{Cómo referenciar este artículo:}

Rodríguez-Castro, M., López-Cepeda, A. M., y Soengas-Pérez, X. (2022). La televisión educativa en España: la oferta de Atresmedia, Mediaset y RTVE. RIED. Revista Iberoamericana de Educación a Distancia, 25(1), pp. 203-221. https:// doi.org/10.5944/ried.25.1.30952

\section{Resumen}

En este artículo hacemos un breve recorrido por los orígenes y la evolución de la televisión educativa en España, y después nos detenemos en la oferta de los tres principales grupos audiovisuales para realizar un retrato de la situación actual. Para ello, se parte de una primera fase de revisión de la literatura científica, empleando después como metodología específica el análisis de contenido de la programación de Atresmedia, Mediaset y RTVE, durante la semana del 19 al 25 de abril de 2021, utilizando una ficha con unas variables que permiten identificar las características de los programas educativos que se emiten en cada canal (duración, horario de emisión, frecuencia, género, tipo de producción y modelo de televisión educativa, según la categorización definida por Pérez Tornero en 2007). La investigación realizada permite concluir que en la televisión educativa en España predomina la producción externa y, además, los formatos adquiridos en la Unión Europea (51,3\%) y los extracomunitarios (48,7\%) son muy similares. Otra de las características es que se amplían los contenidos con otros espacios digitales en las páginas web de los grupos audiovisuales. Esta dinámica confirma que se está produciendo una expansión de la televisión educativa hacia los nuevos medios, que también se pueden explotar con fines pedagógicos. Pero, si la comparamos con la oferta total que existe en Atresmedia, Mediaset y RTVE, la televisión educativa ocupa un espacio marginal en la programación de la televisión en España. 
Palabras clave: televisión educativa; televisión cultural; plataformas digitales; análisis de contenido.

\begin{abstract}
This paper provides an overview on the origins and the evolution of educational television in Spain and, then, studies the current offer of the three main Spanish audiovisual groups, in order to assess the current situation. To achieve this purpose, we first carried out a literature review and, later, we applied a content analysis, being a specific methodology, to the television programming of Atresmedia, Mediaset and RTVE during the week between the $19^{\text {th }}$ and the $25^{\text {th }}$ of April, 2021. We have utilized an analysis sheet that allowed us to identify the main characteristics of the educational programs that are broadcasted in each channel (duration, broadcast schedule, frequency, genre, type of production and model of educational television, according to the categorization of Pérez Tornero, 2007). Based on the conducted research, it can be concluded that educational television in Spain is dominated by external production content and that the percentage of formats produced within the European Union $(51,3 \%)$ and outside the EU $(48,7 \%)$ are very similar. Another feature that has been identified is that television contents are expanded towards the digital arena, in the websites of the media groups within our sample. This dynamic confirms that there is an expansion of educational television towards new media, which can also be exploited for educational purposes. However, educational television in Atresmedia and Mediaset occupies a marginal space in Spanish television programming compared to RTVE.
\end{abstract}

Keywords: educational television; cultural television; digital platforms; content analysis.

En marzo del 2020, la irrupción de la pandemia de COVID-19 forzó el cierre de los centros educativos, confinando al alumnado en sus hogares y trasladando toda la actividad docente al entorno digital. La obligación de quedarse en casa supuso, entre otras alteraciones, un aumento del consumo mediático, tanto en la televisión lineal como a través de plataformas de vídeo bajo demanda (Montaña Blasco et al., 2020). En este contexto tan complejo, la televisión se convirtió en una aliada no sólo a la hora de transmitir información de servicio público (Mihelj et al., 2021) y proporcionar una fuente de entretenimiento y desconexión, sino también recuperando una de sus funciones más marginadas (Serrano y Ojeda Castañeda, 2007; Grummell, 2009), la educativa.

Las televisiones públicas y privadas modificaron su parrilla para incluir programación educativa destinada a poner en contacto al alumnado con el currículo educativo mientras las aulas permaneciesen cerradas (EBU, 2020; Balanzategui et al., 2021; Samudio Granados et al., 2021; Montenegro, 2021). En España, la Corporación de Radio y Televisión Española (RTVE) y el Ministerio de Educación y Formación Profesional coordinaron la iniciativa "Aprendemos en casa", que consistió en la emisión de contenidos educativos dirigidos al alumnado de entre 6 y 16 años, tanto en La 2 como en Clan, la cadena infantil de la corporación; y "EduClan”, una 
propuesta similar, aunque centrada en los medios digitales (web, apps y televisiones conectadas). También los medios privados reservaron espacio para la emisión de contenidos educativos: Boing, el canal infantil de Mediaset, programó "Real Mom", cuyo objetivo era enseñar inglés a los más pequeños.

En este artículo se analiza cuál es la situación actual de la televisión educativa en España, un año después de su revitalización como consecuencia de la irrupción de la pandemia de COVID-19. La revisión de la programación de los tres grupos de televisión de mayor alcance en España (Mediaset, Atresmedia y RTVE), proporciona una radiografía de la oferta educativa de las televisiones, tanto en su emisión lineal como en sus servicios digitales.

\section{LA TELEVISIÓN EDUCATIVA EN TIEMPOS DE CONVERGENCIA}

La televisión cuenta con un innegable carácter educativo inherente a su naturaleza de medio de comunicación de masas, capaz de hacer llegar mensajes a grandes audiencias y segmentos diversos de la población (Molina Santonja, 2020). En Europa, donde la televisión se desarrolló mayormente bajo el paradigma del servicio público, este medio contó desde sus orígenes con objetivos educativos asentados en "sueños de mayor igualdad social, así como de un aumento de la participación en procesos y prácticas sociales" (Lukács, 2007, p. 200). La experiencia de las televisiones públicas en el campo de la educación varía en función de cada contexto nacional, y puede articularse a partir de la creación de departamentos especializados en educación dentro de las televisiones públicas generalistas, como sucedió en la $\mathrm{BBC}$, o con el establecimiento de organizaciones independientes dedicadas en exclusiva a la producción y difusión de contenidos televisivos de corte educativo, como la Utbildungsradion (UT) sueca.

La liberalización del mercado supuso una considerable erosión de los contenidos educativos dentro dela oferta televisiva. Las televisiones privadas no mostraroninterés en este tipo de contenidos por su escasa capacidad de generar ingresos, mientras que en las televisiones públicas, que tradicionalmente se habían caracterizado por incluir algún tipo de oferta educativa, también quedó relegada a un segundo plano ante la necesidad de competir bajo las premisas de los datos de audiencia (Francés i Doménech, 2005; Lukács, 2007). Esta situación de declive de la televisión educativa, sin embargo, puede ser superada gracias a los beneficios de la digitalización y de la convergencia, que permiten ampliar, complementar y personalizar la oferta educativa de las televisiones (públicas y privadas) con materiales disponibles en sus páginas web y aplicaciones móviles (Albero-Andrés, 2001; Zorrilla Abascal, 2016).

Además, es necesario revisar la definición de televisión educativa para adaptarla a los avances sociales y tecnológicos (Quinteiro Otero, 2014), porque esta definición ha sido objeto de debate desde sus orígenes y todavía conviven múltiples interpretaciones, según la óptica desde la que se observe: su aplicación a distintos niveles escolares (desde preescolar hasta la formación universitaria), su 
modelo educativo (conductista, cognitivo o constructivista) o su orientación hacia la enseñanza formal o informal (Serrano y Ojeda Castañeda, 2007).

Una de las categorizaciones clásicas más asentadas en la literatura académica es la propuesta por Lothar Humburg, quien considera que existen tres modelos de televisión educativa: el modelo de enriquecimiento, el de enseñanza directa y el de contexto (Meyer, 1992). El modelo de enriquecimiento o televisión escolar se plantea para su uso en centros escolares o formativos, por lo que es la institución educativa la que predomina sobre el medio televisivo (Quinteiro Otero, 2014). El modelo de enseñanza directa tiene como objetivo sustituir, puntual o totalmente, al sistema educativo, proporcionando una vía de formación fundamental en contextos de escaso desarrollo económico o en momentos de aislamiento, como sucedió durante la pandemia de COVID-19. Por sus particularidades, el modelo de enseñanza directa es "el único sobre el que reposa la autonomía de la televisión educativa como medio de instrucción y formación frente a la cooperación" de los otros dos modelos (Quinteiro Otero, 2014). Por último, el modelo de contexto concibe la televisión como un instrumento más dentro del proceso de educación, aprendizaje y actividad cultural de la sociedad.

Este último modelo plantea la dificultad de trazar un límite claro entre la televisión educativa y la televisión cultural. La frontera entre ambos conceptos es tan difusa que pueden llegar a entenderse como uno solo. Así, autores como Pérez Tornero $(1994 ; 2007)$ hablan de la televisión educativo-cultural para referirse a los contenidos televisivos cuya "función esencial es contribuir a la ampliación de la educación y la formación de los espectadores integrándolos en un sistema cultural dinámico" (Pérez Tornero, 1994, p. 172). Sin embargo, a pesar de que los procesos de convergencia no sólo hibridan medios, sino también formatos y temáticas, es necesario establecer una diferenciación entre la televisión educativa y la cultural (Emanuel, 1993).

En este sentido, resulta especialmente pertinente la distinción elaborada por Serrano y Ojeda Castañeda (2007), quienes consideran que la televisión educativa se ubica a medio camino entre una televisión escolar, pedagógica, instructiva o didáctica, y la televisión cultural es divulgativa o del conocimiento. Para Serrano y Ojeda Castañeda (2007), lo que distingue a la televisión educativa es el desarrollo de unos contenidos y estrategias específicas, expresadas a través del lenguaje televisivo y que, aunque no reflejen de forma directa los contenidos curriculares de la educación reglada, sí que cuentan con un trasfondo didáctico, dirigido a ampliar la visión del mundo de los espectadores. Así, lo que define a la televisión educativa, más que sus contenidos o formatos (que pueden ser muy diversos, desde un magazín hasta una serie de ficción), es su vocación pedagógica. Esta intencionalidad, por lo tanto, es lo que marca la diferencia entre la televisión educativa y la televisión cultural, ya que ésta última, a pesar de tener potencial educativo, "no está concebida desde su origen y en todas sus fases de elaboración con una intencionalidad educativa" (García Mantilla et al., 2006, p. 114). 
En los últimos años la televisión educativa se ha enriquecido gracias a la extensión de sus contenidos a los nuevos medios digitales. Ya en la década de los 90 algunas televisiones públicas europeas comenzaron a lanzar servicios educativos en línea (Lukács, 2007; Grummell, 2009). Estas estrategias innovadoras no fueron siempre bien recibidas en un mercado todavía incipiente, lo que en casos como el del BBC Digital Curriculum concluyó con la cancelación del servicio debido a las enérgicas protestas del sector privado (Michalis, 2012). En la actualidad, con un mercado digital mucho más maduro y relativamente consolidado gracias a los avances, las televisiones públicas, y también las comerciales, amplían su oferta educativa en sus páginas web y en aplicaciones y plataformas específicas.

Los nuevos medios traen consigo importantes beneficios educativos y pedagógicos que no estaban presentes en la televisión tradicional, como la posibilidad de ampliar el catálogo de contenidos ofertados, su interactividad y la personalización, tanto de los propios contenidos como del momento, el espacio y el dispositivo en el que se consumen. Sin embargo, su creciente popularidad requiere también una alfabetización mediática y digital que permita a los usuarios producir, difundir y consumir contenidos de forma crítica y consciente (Gutiérrez y Tyner, 2012).

\section{ORÍGENES Y EVOLUCIÓN DE LA TELEVISIÓN EDUCATIVA EN ESPAÑNA}

La historia de la televisión educativa en España está marcada por el papel de la radiotelevisión pública, tanto a nivel estatal como autonómico. Al igual que sucedió en otros países europeos, donde las televisiones públicas fueron los principales agentes impulsores de la televisión educativa (Grummell, 2009), en España fue RTVE la que empezó a experimentar con este tipo de contenidos, con la particularidad de que los primeros pasos de la televisión educativa española se produjeron bajo la dictadura franquista (González-Delgado, 2020) y en una sociedad con niveles de escolarización inferiores a los de las democracias europeas.

La programación de contenidos educativos en RTVE comenzó en 1958, cuando se empezó a emitir, de lunes a sábado, el programa "Aula TV", un formato muy breve (entre 2 y 3 minutos), que servía de presentación de los contenidos pedagógicos que la cadena pública emitiría a continuación. Un año más tarde, en 1959, se estrenó "Universidad TV", un espacio de una hora de duración, que se emitía de lunes a jueves, de 20:00 a 21:00 horas, en el que un profesor universitario impartía una lección sobre diversos temas. En 1961, la programación educativa de TVE se amplió con "Escuela TV", con el objetivo de impartir cursos relacionados con la formación profesional (Antona Jimeno, 2014).

La inclusión de formatos educativos más amplios y ambiciosos en la parrilla de programación de RTVE se produjo con los programas de colaboración impulsados desde el Ministerio de Educación. Para González-Delgado (2020) la implicación del régimen franquista con la televisión educativa obedece a la presión ejercida 
por organismos internacionales (como la UNESCO) para "ampliar el marco de escolarización de todos los niveles de enseñanza, como una forma de alcanzar el desarrollo económico" (González-Delgado, 2020, p. 620). Por eso, en 1963 se creó el Centro Nacional de Enseñanza Media por Radio y Televisión, en línea con un discurso de modernización que no supuso la desaparición de los valores del nacionalcatolicismo en sus contenidos.

Desde entonces, el papel del Ministerio de Educación es fundamental para entender el desarrollo de la televisión educativa en España, muy centrada en su primera etapa en la formación y alfabetización de adultos. Los programas "Imágenes para saber" (con su versión veraniega "Imágenes para descansar") y "TV escolar" suponen los mayores exponentes de esta época. "TV escolar" se comenzó a emitir en 1968, de lunes a viernes, y se mantuvo de forma estable en la parrilla de TVE durante dos años, hasta que fue reemplazado por otro programa de formación de adultos (Pérez Tornero, 2007).

Las décadas siguientes se caracterizan por una erosión de la programación educativa en la televisión pública. En 1982, ya en democracia, el Ministerio de Educación y Ciencia anunció un proyecto de sistema de radiotelevisión educativa que nunca se llegó a materializar (Pérez Tornero, 2007) y no es hasta la década de los 90 cuando TVE vuelve a apostar por la programación educativa con el proyecto "Televisión escolar", acordado entre RTVE y el Ministerio de Educación. En el marco de este acuerdo se desarrolla el formato "La aventura del saber", un programa dirigido por José Manuel Pérez Tornero, que comenzó sus emisiones en 1992 y que se mantiene en la parrilla de La 2 en la actualidad. "La aventura del saber" se planteó como un magazín educativo de tres horas (después reducidas a una), emitido en la franja matinal de La 2 y pensado para cumplir un triple objetivo: educación de adultos, apoyo al sistema educativo y cooperación con la educación a distancia (Quinteiro Otero, 2014).

Entre las experiencias más recientes en el campo de la televisión educativa en España se encuentra la creación, en el año 2005, de canal de televisión infantil Clan, de RTVE, aunque en su programación los contenidos didácticos se diluyen en una oferta de programación de entretenimiento infantil y juvenil (Quinteiro Otero, 2014).

Las experiencias de las televisiones públicas autonómicas con la televisión educativa son todavía más esporádicas (Ikusgela, en EiTB, o Preescolar na casa, en la TVG, por ejemplo) y, en gran parte, se encuentran más próximas a la televisión cultural que a la educativa (Pérez Tornero, 2007). Y la televisión comercial apenas ha desarrollado formatos vinculados a la televisión educativa, con la excepción de la llegada de canales temáticos de transmisión por cable o satélite especializados en la divulgación cultural y científica, entre los que también destacó alguna experiencia genuinamente educativa, como el caso del canal "Beca TV", del Grupo Planeta, que operó entre el 2001 y el 2003. 


\section{METODOLOGÍA}

\section{a. Muestra}

El objetivo de este artículo es realizar un retrato de la situación actual de la televisión educativa en los canales de los principales grupos de televisión en abierto a nivel nacional: Atresmedia (Antena 3, La Sexta, Neox, Nova, Mega y Atreseries), Mediaset (Telecinco, Cuatro, Factoría de Ficción, Boing, Divinity, Energy y Be Mad) y RTVE (La 1, La 2, Clan, 24h y Teledeporte). Además, también analizamos cómo se amplían los contenidos televisivos con otros contenidos digitales en las páginas web de los canales objeto de estudio, con el propósito de determinar si se está produciendo una expansión de la televisión educativa hacia los nuevos medios o si éstos no se están explotando con fines pedagógicos.

\section{b. Hipótesis, procedimiento y análisis de datos}

La hipótesis de trabajo es que la televisión educativa ocupa un espacio marginal en la programación televisiva española, algo que está más acentuado en los canales públicos que en los privados. Para ello, el procedimiento seguido fue el de analizar la programación televisiva de los canales que componen la muestra durante la semana del 19 al 25 de abril de 2021, para identificar los programas educativos que se emitían en ese periodo. También se analizaron las páginas web de los tres grupos televisivos que conforman la muestra porque nos interesan las secciones dirigidas al público infantil, para averiguar de qué forma se estructuran los contenidos, qué fines educativos y pedagógicos persiguen, y de qué forma se explotan las posibilidades que ofrecen los nuevos medios para realzar la misión de la televisión educativa.

El diseño metodológico parte en una primera fase de revisión de la literatura científica, propia de la investigación secundaria (Codina, 2017) que ha permitido conocer las principales aportaciones al estado de la cuestión. Luego, como metodología específica utilizamos el análisis de contenido, basándonos en una ficha ya testada en otros trabajos con características similares. Debido a la escasez de estudios recientes sobre el objeto de estudio, el diseño metodológico final incluye una combinación de criterios utilizados en otras investigaciones sobre televisión de calidad (Pujadas-Capdevila, 2011), contenidos infantiles (Ibañez, Pérez y Zabildea, 1999; Digón-Regueiro, 2008) o ambos criterios (Vázquez-Barrio, 2009). No obstante, debido a la singularidad del tema, la versión final de la ficha de análisis se adaptó a los objetivos de la investigación, siempre teniendo presente la categorización de televisión educativa definida por Pérez Tornero (2007, pp. 44-45). 


\section{c. Instrumento. Ficha de análisis}

En esta investigación se hizo uso de una ficha de análisis en la que se contemplaron las siguientes variables: canal, duración, horario de emisión, frecuencia de emisión, género televisivo, tipo de producción (propia o externa) y modelo de televisión educativa en la que se insertan, a partir de la categorización definida por Pérez Tornero (2007, pp. 44-45), que consta de cinco modalidades:

- Televisión escolar: directamente relacionada con el sistema educativo, desarrolla los contenidos marcados por el currículo oficial. Pérez Tornero (2007) distingue entre la televisión que sirve de extensión de la escuela, supliendo sus carencias y la que funciona como contexto o refuerzo, complementando al sistema educativo.

- Televisión de formación profesional: está orientada al desarrollo de competencias profesionales y a la formación universitaria de públicos adultos y jóvenes.

- Televisión del conocimiento: dirigida a una audiencia generalista, comprende tanto la divulgación como la formación en ámbitos relacionados con las demandas culturales de la ciudadanía.

- Televisión científico-cultural (generalista o temática): se basa en la divulgación de contenidos (generales o temáticos) de carácter científico o cultural, como el arte, la historia o la tecnología.

- Televisión infantil: Pérez Tornero (2007) parte de la idea de que la programación infantil no puede dejar de ser, salvo excepciones, educativa, aunque emplee modelos lúdicos y de entretenimiento, una idea reafirmada más recientemente por Fuenzalida (2016).

\section{LA TELEVISIÓN EDUCATIVA. MEDIOS PÚBLICOS VS MEDIOS PRIVADOS}

Tradicionalmente, la mayor parte de los programas educativos en España se localizaban en la televisión pública, y eran los segundos canales los que absorbían la mayor parte de la oferta televisiva de contenidos educativos (Gómez-Calderón y González-Cortés, 2004), pero ahora se localizan también espacios educativos en algunos canales de las principales cadenas privadas. Además, destacan los canales temáticos infantiles, en donde la totalidad de la programación es prácticamente educativa.

Sin contabilizar la programación infantil, los resultados muestran que el número de programas educativos es el mismo en la televisión pública estatal que en las cadenas de los principales grupos mediáticos privados (Atresmedia y Mediaset), aunque al analizar el tiempo de emisión, los resultados muestran que de lunes a domingo las cadenas privadas emiten 325 minutos de programas educativos $(3,22 \%$ de las horas totales de emisión de una semana), frente a los 755 minutos de la pública (el 7,5\% de las horas totales de emisión de una semana). En las cadenas privadas 
todos los programas de estas características se emiten por la mañana, en general a primera hora, mientras que La 1 de TVE emite de lunes a viernes de 20.30 a 21.00 horas y los domingos de 20.25 a 21.0o horas Aquí la Tierra.

Por géneros, localizamos dos espacios de reportajes, uno en La 1 de TVE, Seguridad Vital, que transmite valores sobre seguridad vial y movilidad sostenible, y otro en Neox de Atresmedia, Hazte Eco, que trata sobre el cuidado del medio ambiente y el respeto por los animales. En Mega se emite una serie documental, Ciencia para aficionados, y en La 1 un magazine, Aquí la Tierra. Además, hay cinco programas divulgativos de diferentes temáticas. Dos de ellos sobre lectura, Mil palabras y Woman, en Cuatro, y Crea Lectura en Mega y La Sexta, uno de salud, ¿Qué me pasa Doctor?, también en Mega y La Sexta, uno sobre cuidado animal, Iumiuky, en Cuatro, y uno de divulgación variada, La Aventura del Saber, en La 2. Y también destacan tres programas educativos para adultos en La 2: Inglés en TVE, That's English y UNED.

Los canales temáticos dirigidos a niños emiten prácticamente durante toda la semana programas educativos porque una televisión infantil no puede dejar de ser educativa (Quinteiro-Otero, 2014, p. 94, a partir de Pérez Tornero, 2007). La excepción a esta tendencia es el canal Neox, de Atresmedia, que en un primer momento estaba dirigido a un público de entre 7 y 12 años, pero en la actualidad su público potencial son adolescentes de entre 13 y 22 años. Esta cadena sólo tiene un programa contenedor dirigido a niños.

El resto de los espacios infantiles se emiten en Clan de TVE y Boing de Mediaset. Ambos son canales infantiles, aunque en Clan de TVE también hay varios programas juveniles. Las dos cadenas tienen 24 horas ininterrumpidas de programación. En la parrilla de Clan, se emiten 41 programas diferentes a la semana, de los cuales 35 son infantiles y, por lo tanto, educativos. Al analizar los contenidos se advierte que el 91,4\% de los espacios infantiles que emite Clan son dibujos animados, el 5,7\% series de ficción y el 2,8\% programas que desarrollan en clave de humor el currículo oficial de los menores. En Boing existe una tendencia similar, con 22 espacios educativos diferentes, de los cuales el 90,9\% son dibujos animados y el 9,1\% series de ficción.

\section{TIPOS DE TELEVISIÓN EDUCATIVA EN ESPAÑA}

\section{Formatos de televisión educativa}

Los formatos de los espacios educativos en la televisión estatal en España varían según las cadenas donde se emiten. Si diferenciamos entre canales generalistas y temáticos, en los primeros el formato dominante son los programas divulgativos (41,7\%), seguidos de la formación para adultos (25\%), reportajes $(16,7 \%)$, series documentales (8.3\%) y magazines (8,3\%). En los canales infantiles hay un predominio de los dibujos animados $(89,7 \%)$, tanto en las cadenas públicas como en las privadas, 
frente a otros contenidos como las series de ficción (6,8\%), espacios con formación para niños $(1.7 \%)$ y otros $(1,7 \%)$ (Ver tabla 1$)$.

\section{Tabla 1}

Formatos de la televisión educativa en España

\begin{tabular}{|c|c|c|c|c|c|c|c|}
\hline & Reportajes & $\begin{array}{r}\mathrm{Se} \\
\text { docun }\end{array}$ & 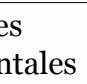 & Magazines & Divulgativos & $\begin{array}{c}\text { Formación } \\
\text { para adultos }\end{array}$ & Total \\
\hline $\begin{array}{l}\text { Canales } \\
\text { generalistas }\end{array}$ & $16.7 \%$ & & & $8,3 \%$ & $41,7 \%$ & $25 \%$ & $100 \%$ \\
\hline Públicos & $8,3 \%$ & & & $8,3 \%$ & $8,3 \%$ & $25 \%$ & $50 \%$ \\
\hline \multirow[t]{2}{*}{ Privados } & $8,3 \%$ & & & $\mathrm{O}$ & $33,4 \%$ & $0 \%$ & $50 \%$ \\
\hline & \multicolumn{2}{|c|}{ Dibujos animados } & \multicolumn{2}{|c|}{$\begin{array}{l}\text { Series de } \\
\text { Ficción }\end{array}$} & $\begin{array}{l}\text { nación para } \\
\text { niños }\end{array}$ & Otros & Total \\
\hline $\begin{array}{l}\text { Canales } \\
\text { temáticos } \\
\text { infantiles }\end{array}$ & \multicolumn{2}{|c|}{$89,7 \%$} & \multicolumn{2}{|c|}{$6,8 \%$} & $1,7 \%$ & $1,7 \%$ & $100 \%$ \\
\hline Públicos & \multicolumn{2}{|c|}{$55,2 \%$} & \multicolumn{2}{|c|}{$3.4 \%$} & $1,7 \%$ & $0 \%$ & $60.4 \%$ \\
\hline Privados & \multicolumn{2}{|c|}{$34,5 \%$} & \multicolumn{2}{|c|}{$3.4 \%$} & $0 \%$ & $1,7 \%$ & $39,6 \%$ \\
\hline
\end{tabular}

Fuente: elaboración propia en abril de 2021

Sin establecer diferencias entre canales generalistas y temáticos infantiles, en la televisión educativa en España predominan los dibujos animados $(74,2 \%)$, frente a los espacios divulgativos (11,5\%), series de ficción infantiles $(5,7 \%)$, programas de formación $(5,7 \%)$, reportajes $(2,9 \%)$, series documentales $(1,4 \%)$, magazines $(1,4 \%)$ y otros programas infantiles $(1,4 \%)$. 


\section{Figura 1}

Formatos predominantes en la televisión educativa en España

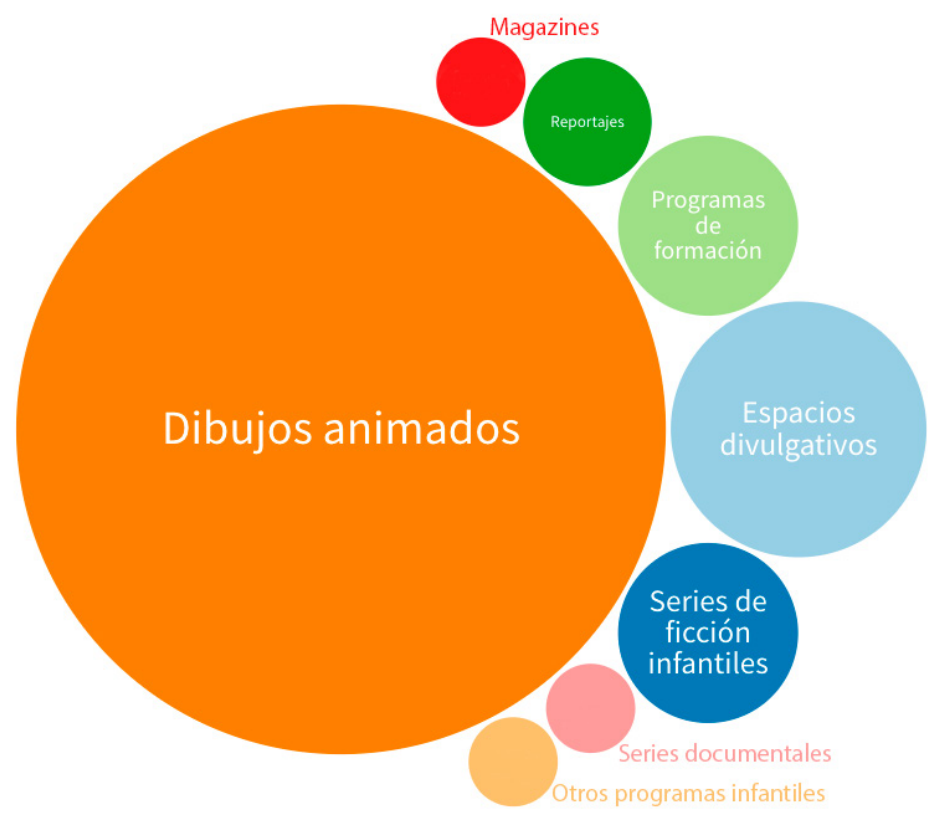

\section{La televisión educativa en España según su intencionalidad}

Los espacios de televisión educativa también se pueden clasificar en varias categorías según su intencionalidad didáctica: televisión escolar, televisión de formación profesional, televisión del conocimiento, televisión científico-cultural y televisión infantil (Pérez Tornero, 2007).

En España, tanto en las cadenas públicas como en las privadas, predominan los programas infantiles basados en modelos de entretenimiento $(81,5 \%)$ y se caracterizan por ser espacios muy reducidos que se emiten en las cadenas temáticas infantiles. Pero en la programación de la televisión educativa también encontramos 9 espacios, $(12,8 \%)$, que se pueden clasificar como televisión del conocimiento o televisión científico cultural generalista porque abordan distintos temas desde una perspectiva didáctica: valores de seguridad vial, medio ambiente, animales, divulgación científica y literaria. En cambio, la televisión de formación profesional sólo tiene presencia la segunda cadena de TVE, La 2, con tres espacios orientados a la formación del público adulto: Inglés en TVE, That's English y UNED. Y la televisión escolar aparece representada en un espacio, Clan, el canal infantil de la televisión 
pública. Aprendemos con Clan es un programa que desarrolla los contenidos del currículo oficial de los menores de forma amena y humorística.

\section{Figura 2}

Distribución de la televisión educativa en función de su intencionalidad

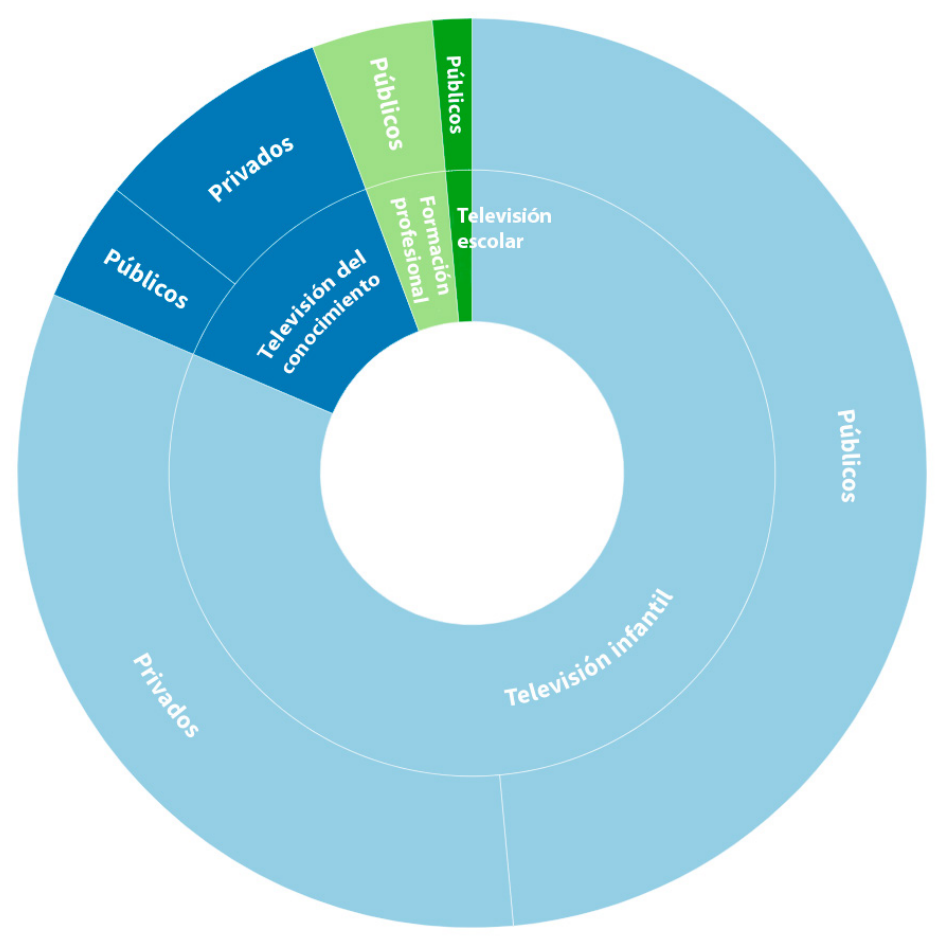

\section{La producción en la televisión educativa}

En la televisión educativa de España predomina la producción externa. Sólo el $12 \%$ es producción propia o coproducción con otra cadena o con una productora. Pero si analizamos la procedencia, la producción de la Unión Europea $(51,3 \%)$ y la extracomunitaria $(48,7 \%)$ son muy similares. Dentro de la Unión Europea, predominan los programas producidos en España (27,1\%), seguidos de los producidos en Francia (8,6\%), Italia (5,7\%) e Irlanda (1,4\%), que también se emiten en España. Y fuera de la Unión Europea destacan las producciones de EE.UU. (24,3\%), Reino Unido (10\%), Japón (5,7\%), Canadá (2,9\%) y en menor medida Rusia $(1,4 \%)$ e Islandia $(1,4 \%)$. Pero también hay producciones mixtas de varios países 
europeos $(7,1 \%)$, un país europeo y otro externo a la UE $(2,9 \%)$ o de dos países no pertenecientes a Europa $(1,4 \%)$.

Si diferenciamos entre canales generalistas y temáticos se observa que, mientras en los primeros dominan los contenidos europeos (83,3\%), todos de producción española, en las cadenas infantiles los espacios educativos tienen una procedencia más diversa, y son mayoritarios los contenidos no europeos: Estados Unidos (27,6\%), España (15,5\%), Francia (10,4\%), Reino Unido (10,4\%), Italia (6,7\%), Japón $(6,7 \%)$, Canadá (3,5\%), Islandia (1,7\%), Irlanda (1,7\%) y Rusia (1,7\%). Además, algunos espacios son producidos por varios países europeos $(8,6 \%)$, un país europeo y uno no perteneciente a la UE $(3,5 \%)$ o bien dos países no europeos $(1,7 \%)$.

\section{Figura 3}

Distribución de los formatos de televisión educativa según su origen

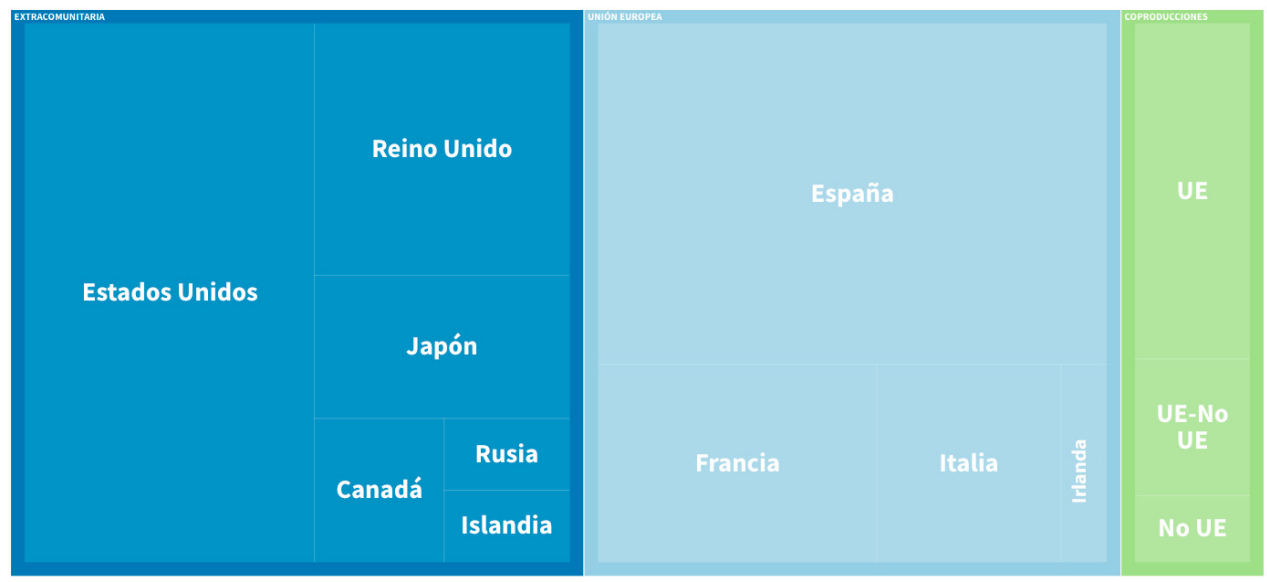

Entre las televisiones públicas y las privadas se observan importantes diferencias. Los canales públicos prefieren contenidos educativos españoles $(31,7 \%)$, aunque también ofrecen formatos ingleses $(12,2 \%)$, italianos $(9,8 \%)$, franceses $(9,8 \%)$ y mixtos de varios países europeos (9,8\%). Y retransmiten muchos menos contenidos educativos de otros países como EE.UU. (7,3\%), Canadá (4,9\%), mixtos de un país europeo y otro no comunitario (4,9\%), Rusia $(2,4 \%)$, Islandia $(2,4 \%)$, Irlanda $(2,4 \%)$ o de varios países extracomunitarios (2,4\%). En cambio, las cadenas privadas de los dos principales grupos mediáticos de España apuestan por los contenidos educativos de Estados Unidos (48,3\%) frente a los producidos en España (20,7\%), pero también hay formatos japoneses $(13,8 \%)$, ingleses $(6,9 \%)$, franceses $(6,9 \%)$ o franco-belgas $(3,4 \%)$. 


\section{La televisión educativa en las plataformas digitales}

El análisis de la oferta educativa en las webs y en las plataformas digitales de los medios analizados confirma la tendencia señalada en la programación televisiva: la oferta educativa es mayor en los medios públicos que en los privados. Los grupos analizados ofrecen la programación en sus plataformas digitales (Atresplayer, de Atresmedia, MiTele, de Mediaset y RTVE a la carta), pero la única de estas plataformas que incluye de forma explícita la categoría "educación" es la de la televisión pública, donde los usuarios pueden visionar programas que ya se han emitido. También resulta interesante la categoría "Ciencia y tecnología" de la misma plataforma, que permite acceder a programas como Órbita Laika. Ni Atresplayer ni MiTele incluyen categorías similares en su oferta digital.

Las tres plataformas sí coinciden en incluir un apartado dirigido específicamente al público infantil: Atresmedia Kidz, MiTele Wala y Clan RTVE. La oferta educativa en Internet de Atresmedia se limita a 62 series de animación a la carta y 5 de ficción infantil. Entre los dibujos animados destaca la franquicia "Érase una vez...", de la que se ofrecen cinco series (el espacio, el cuerpo humano, el hombre, los inventores y los exploradores). Al contrario de lo que sucede con la oferta educativa digital de Mediaset y RTVE, Atresmedia no incluye en sus webs contenidos extra o complementarios de los formatos televisivos dirigidos al público infantil.

MiTele, el servicio a la carta de Mediaset, estrenó en abril de 2021 tres canales digitales dirigidos a audiencias diferentes. Entre ellos se encuentra MiTele Wala!, un espacio pensado para el público infantil, todavía con pocos contenidos, pero interesantes desde el punto de vista de la televisión educativa. "Cuentos animados FLUYE” forma parte del proyecto Fluye, promovido por Danone, Mediaset España y la Fundación Trilema, que tiene como objetivo educar a la infancia en hábitos de salud física, mental y emocional. Dentro de MiTele Wala! se incluyen también los formatos "Real Mom", que está orientado al aprendizaje de inglés; y "Descubre con Tadeo", una serie de animación fruto de la colaboración entre Mediaset España y la Fundación Española para la Ciencia y la Tecnología.

La oferta educativa de Mediaset se amplía también en la página web de su canal infantil, Boing, donde se puede acceder a vídeos y juegos relacionados con las series emitidas en este canal temático. El componente pedagógico aquí no es tan claro como en la oferta de MiTele Wala!, aunque hay contenidos incluidos en la categoría de televisión infantil. Pero la oferta educativa digital para el público infantil más ambiciosa es la de RTVE. Como sucedía en los otros dos grupos analizados, en la página web de Clan se puede acceder a los contenidos que conforman la parrilla televisiva del canal, pero éstos se complementan con juegos y materiales para descargar. Además de la programación infantil enfocada al entretenimiento de los más pequeños, la página web de Clan también incluye secciones más orientadas a la educación. Para potenciar el aprendizaje de idiomas extranjeros, el programa "Let's Clan" permite ver las series de la cadena temática en inglés, un visionado que se 
puede complementar con las fichas didácticas bilingües, también disponibles en la web.

Con un propósito didáctico explícito, en la misma web de Clan también se incluye la sección "Aprendemos en Clan", fruto de la colaboración entre el Ministerio de Educación y Formación Profesional y el canal infantil de RTVE. En este apartado de la web se puede acceder al espacio educativo presentado por el profesor y youtuber James Van der Lust y la mascota Nacho Capacho, y a los contenidos audiovisuales englobados en distintas categorías, similares a las asignaturas escolares: matemáticas, lengua, ciencias naturales, ciencias sociales y educación física. En este apartado no se ofrecen juegos interactivos ni contenidos descargables. Una última sección de interés pedagógico incluida en Clan es la iniciativa "El mes de...", dedicada cada mes a un tema de interés, como la lectura o el reciclaje, y se ofrecen contenidos audiovisuales diversos y actividades relacionadas con lo propuesto para descargar e imprimir.

Y también es necesario mencionar un espacio de la oferta digital de la televisión pública dentro de la televisión infantil. El canal digital de RTVE dirigido a la audiencia joven, Playz, estrenó en febrero de 2021 el programa “"Whaat!? Tú cómo lo ves”, un programa de divulgación científica presentado por la divulgadora y youtuber Rocío Vidal y por el colaborador de Órbita Laika, Javier Santaolalla. El objetivo de este programa es abordar con rigor científico, mediante la colaboración de expertos, temas que resulten de interés para las audiencias jóvenes, como el medio ambiente, la evolución o los negocios.

\section{DISCUSIÓN Y CONCLUSIONES}

El análisis presentado en este artículo pone de manifiesto la escasa presencia de formatos vinculados a la televisión educativa en la programación de los principales grupos de televisión a nivel nacional: Antena 3, Mediaset y RTVE. Los resultados de la investigación apuntan a una situación marginal de este tipo de contenidos, especialmente en los canales comerciales. El impacto de la crisis económica del 2008 en la programación de corte educativo y cultural que apuntaba Molina Santoja (2020) no ha sido revertido en los últimos años y, dada la escasa rentabilidad de la programación educativa, es la televisión pública la que mantiene un mayor porcentaje de emisiones con componentes pedagógicos. La hipótesis que se planteaba al inicio de este artículo, en la que partíamos de que los canales públicos contarían con una mayor oferta educativa, se confirma.

Sin establecer diferencias entre canales generalistas y temáticos infantiles, en la televisión educativa en España predominan los dibujos animados $(74,2 \%)$, frente a los espacios divulgativos (11,5\%), series de ficción infantiles $(5,7 \%)$, programas de formación $(5,7 \%)$, reportajes $(2,9 \%)$, series documentales $(1,4 \%)$, magazines $(1,4 \%)$ y otros programas infantiles $(1,4 \%)$.

En la televisión educativa de España predomina la producción externa. Sólo el $12 \%$ es producción propia o coproducción con otra cadena o con una productora. 
Y si analizamos la procedencia, la producción de la Unión Europea $(51,3 \%)$ y la extracomunitaria $(48,7 \%)$ son muy similares. Si diferenciamos entre canales generalistas y temáticos se observa que, mientras en los primeros dominan los contenidos europeos (83,3\%), todos de producción española, en las cadenas infantiles los espacios educativos tienen una procedencia más diversa, y son mayoritarios los contenidos no europeos. Entre las televisiones públicas y las privadas se observan importantes diferencias. Los canales públicos prefieren contenidos educativos españoles (31,7\%). En cambio, las cadenas privadas de los dos principales grupos mediáticos de España apuestan por los contenidos educativos de Estados Unidos $(48,3 \%)$ frente a los producidos en España (20,7\%).

Una última característica de la televisión educativa que se deriva de esta investigación es el potencial que ofrecen los medios digitales para ampliar la oferta de emisión lineal tradicional. Los contenidos que ofrecen los canales televisivos analizados en sus páginas web amplían los contenidos televisivos proporcionando actividades tanto online como offline que potencian la interactividad y la interacción. Esta dinámica confirma que se está produciendo una expansión hacia los nuevos medios, que también se pueden explotar con fines pedagógicos.

Es necesario revisar la definición de televisión educativa para adaptarla a los avances sociales y tecnológicos, algo que ya planteaba Quinteiro Otero en 2014. Una de las categorizaciones clásicas más asentadas en la literatura académica es la propuesta de Lothar Humburg, quien considera que existen tres modelos de televisión educativa: el modelo de enriquecimiento, el de enseñanza directa y el de contexto (Meyer, 1992). Pero el modelo de contexto concibe la televisión como un instrumento más dentro del proceso de educación, aprendizaje y actividad cultural de la sociedad, y plantea la dificultad de trazar un límite claro entre la televisión educativa y la televisión cultural. La frontera entre ambos conceptos es tan difusa que pueden llegar a entenderse como uno solo.

La propuesta de categorización de la televisión educativa elaborada por Pérez Tornero (2007) mantiene todavía su vigencia, tal y como se constata en esta investigación, ya queha permitido clasificar distintos tipos de formatos de componente pedagógico. Con todo, la intensificación de la hibridación de los formatos televisivos y la creciente adopción de estrategias transmedia que complementan las emisiones televisivas con contenidos en línea hacen necesario repensar el futuro de la televisión educativa más allá de las parrillas de programación.

\section{RECONOCIMIENTOS}

Este artículo forma parte de las actividades del proyecto de investigación (RTI2018-096065-B-Ioo) del Programa Estatal de I+D+I orientado a los Retos de la Sociedad del Ministerio de Ciencia, Innovación y Universidades y del Fondo Europeo de Desarrollo Regional (FEDER) sobre "Nuevos valores, gobernanza, financiación y 
servicios audiovisuales públicos para la sociedad de Internet: contrastes europeos y españoles".

\section{REFERENCIAS}

Albero-Andrés, M. (2001). Infancia y televisión educativa en el contexto multimedia. Comunicar, 9(17), 116-121. https://doi.org/10.3916/C17-2001-17

Antona Jimeno, T. (2014). Los orígenes de la Televisión Educativa en TVE (1958-1966). Estudios sobre el Mensaje Periodístico. https://doi.org/10.5209/ rev ESMP.2014.v20.45099

Balanzategui, J., Burke, L., y McIntyre, J. (2021). 'What would Bandit do?': reaffirming the educational role of Australian children's television during the COVID-19 pandemic and beyond. Media International Australia, 178(1). https:// doi.org/10.1177/1329878X20948272

Codina, L. (2017). Revisiones sistematizadas y cómo llevarlas a cabo con garantías: Systematic reviews y SALSA Framework. https://www.lluiscodina.com/revisionsistematica-salsa-framework/

Digón-Regueiro, P. (2008). Programación infantil y tv sensacionalista: entretener, desinformar, deseducar. Comunicar, 16(31), 65-76. https://doi.org/10.3916/ c31-2008-01-008

EBU (2020). Lessons from lockdown exploring children's broadcasting. Ginebra: European Broadcasting Union. https://www.ebu.ch/news/2020/05/ ebu-lessons-from-lockdown-exploringchildrens-broadcasting

Emanuel, S. (1993). Cultural Television: Western Europe and the United States. European Journal of Communication, 8(2), 131-147. https://doi. org/10.1177/0267323193008002001

Francés i Doménech, M. (2005). ¿Es posible la televisión educativa en la multidifusión digital? Comunicar, 25(2). https://doi. org/10.3916/C25-2005-160
Fuenzalida, V. (2016). La nueva televisión infantil. Fondo de Cultura Económica.

García Mantilla, A., Mayugo i Majó, C., Fernández Baena, J., y Tucho, F. (2006). Televisión comunitaria y televisión educativa: televisión de y para la sociedad civil. Documentación Social. Revista de Estudios Sociales y de Sociología Aplicada, 14O, 111-128.

Gómez-Calderón, B., y González-Cortés, M. E. (2004). La televisión educativa en España. Estructura y audiencias. Universidad de Málaga http://www. cienciared.com.ar/ra/usr/9/370/fec 01 com gomez b.pdf

González-Delgado, M. (2020). «Estar a la altura de nuestro tiempo»: la televisión educativa, la UNESCO y la modernización de la enseñanza en el franquismo. Hispania, 8o(265), 597-627. https://doi. org/10.3989/hispania.2020.017

Grummell, B. (2009). The Educational Character of Public Service Broadcasting. European Journal of Communication, 24(3), 267-285. https://doi. org/10.1177/0267323109336756

Gutiérrez, A., y Tyner, K. (2012). Educación para los medios, alfabetización mediática y competencia digital. Comunicar, 38, 3139. https://doi.org/10.3916/C38-201202-03

Ibáñez, J. L., Pérez, J. C., y Zabildea, B. (1999). Televisión y programación infantil en Euskadi. Zer: Revista de Estudios de Comunicación, 7.

Lukács, M. (2007). Education in the Transition to Public Service Media. En G. F. Lowe y J. Bardoel (Eds.), From Public Service Broadcasting to Public Service Media (pp. 199-214). Nordicom. 


\section{Rodríguez-Castro; A. M. López-CEpedA; X. Soengas-PÉreZ

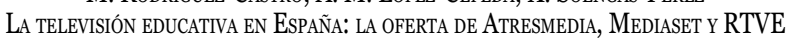

Meyer, M. (1992). Aspects of School Television in Europe. Saur.

Michalis, M. (2012). Balancing public and private interests in online media: the case of BBC Digital Curriculum. Media, Culture \& Society, 34(8), 944-960. https://doi. org/10.1177/0163443712455557

Mihelj, S., Kondor, K., y Štětka, V. (2021). Audience Engagement with COVID-19 News: The Impact of Lockdown and Live Coverage, and the Role of Polarization. Journalism Studies. https://doi. org/10.1080/1461670X.2021.1931410

Molina Santonja, M. D. (2020). Análisis de la capacidad formativa de la televisión. Enseñanza \& Teaching: Revista Interuniversitaria de Didáctica, 38(2), 87-112. $\quad$ https://doi.org/10.14201/ et202038287112

Montaña Blasco, M., Ollé Castellà, C., y Lavilla Raso, M. (2020). Impacto de la pandemia de Covid-19 en el consumo de medios en España. Revista Latina de Comunicación Social, 78, 155-167. https://doi.org/10.4185/RLCS-20201472

Montenegro, A. M. (2021). Costa Rica's educational scenario in times of COVID-19 pandemic. Educational Media International. https://doi.org/10.1080/0 9523987.2021.1930483

Pérez Tornero, J. M. (1994). El desafio educativo de la televisión. Paidós.

Pérez Tornero, J. M. (2007). La televisión educativo-cultural en España: bases para un cambio de modelo. En J. M. Pérez Tornero et al. (Eds.), Alternativas a la televisión actual (pp. 29-99). Gedisa.
Pujadas-Capdevila, E. (2011). La televisión de calidad. Contenidos y debates. Universitat Autónoma de Barcelona, Universitat Jaume I, Universitat Pompeu Fabra, Universitat de València

Quinteiro Otero, E. (2014). Cara unha televisión educativa centrada no desenvolvemento global do neno: o caso de Pocoyó [Tesis Doctoral, Universidade de Santiago de Compostela]. Minerva, Repositorio Institucional de la USC. http://hdl.handle.net/10347/13049

Samudio Granados, M., Maruri Castillo, M., y Ponce-Cordero, R. (2021). Voices and images of hope: the rebirth of educational television in times of COVID-19. Journal of Children and Media, 15(1), 65-68. https://doi.org/10.1080/17482798.2020 .1858901

Serrano, M., y Ojeda Castañeda, G. (2007). Televisión educativa y audiencias: una aproximación conceptual. Tecnología y Comunicación Educativas, 21(44), 4-15. https://biblat.unam.mx/hevila/Tecnologiaycomunicacioneducativas/2007/ vol21/no44/1.pdf

Vázquez-Barrio, T. (2009). Evaluación de la calidad de la programación infantil de las televisiones generalistas españolas. Revista Latina de Comunicación Social, 12(64), 844-861. https://doi.org/10.4185/ RLCS-64-2009-866-844-861

Zorrilla Abascal, M. L. (2016). Transmedia intertextualities in educational media resources: The case of BBC Schools in the United Kingdom. New Media \& Society, 18(11), 2629-2648. https://doi. org/10.1177/1461444815590140

\section{PERFIL ACADÉMICO Y PROFESIONAL DE LOS AUTORES}

Marta Rodríguez-Castro es doctora en Comunicación e Información Contemporánea e investigadora en el Grupo Novos Medios de la Universidade de Santiago de Compostela. Sus principales líneas de investigación son los medios de comunicación de servicio público, desde la perspectiva de su regulación, financiación 
y valor público, las políticas de comunicación europeas y la estructura de las plataformas digitales. https://orcid.org/0000-0002-1399-9154

E-mail: m.rodriguez.castro@usc.gal

\section{DIRECCIÓN DE LA AUTORA}

Facultad de Ciencias de la Comunicación

Universidade de Santiago de Compostela

Avda. Castelao, s/n

Santiago de Compostela (España)

Ana María López-Cepeda es doctora en Comunicación y Periodismo y profesora en la facultad de Comunicación de la Universidad de Castilla-La Mancha. Sus principales líneas de investigación son las políticas audiovisuales europeas y españolas, el servicio audiovisual público y los derechos de autor en el campo del periodismo. https://orcid.org/0000-0001-8328-9142

E-mail: ana.lopezcepeda@uclm.es

\section{DIRECCIÓN DE LA AUTORA}

Facultad de Comunicación

Universidad de Castilla-La Mancha

Plaza de la Libertad de Expresión s/n

Cuenca (España)

Xosé Soengas-Pérez es Catedrático de Comunicación Audiovisual en la Universidad de Santiago de Compostela. Sus investigaciones están centradas en el ámbito de la información y de la ficción audiovisual, especialmente en el análisis de los contenidos informativos de radio y de televisión. https://orcid.org/0000-00033246-0477

E-mail: xose.soengas@usc.es

DIRECCIÓN DEL AUTOR

Facultad de Ciencias de la Comunicación

Universidade de Santiago de Compostela

Avda. Castelao, s/n

Santiago de Compostela (España)

Fecha de recepción del artículo: 03/06/2021

Fecha de aceptación del artículo: 04/08/2021

Fecha de aprobación para maquetación: 16/09/2021 